\title{
OS PROBLEMAS DO FINAL DO SÉCULO XVII NA BAHIA SEGUNDO OS ESCRITOS DE GREGÓRIO DE MATOS E SEBASTIÃO DA ROCHA PITA
}

\author{
Cintia Goncalves Gomes Oliveira*
}

\begin{abstract}
RESUMO: Este artigo tem por objetivo estudar a complexa situação econômica enfrentada pela capitania da Bahia, nos anos finais do século XVII, e suas consequências na sociedade, por intermédio de documentos produzidos por dois personagens que viveram aquele momento, mas em situações e com pontos de vista bastante diferentes: o poeta Gregório de Matos $(1636$ - 1696) e o historiador Sebastião da Rocha Pita (1660 - 1738). A análise dos seus escritos é importante na medida em que apresentam leituras de como a crise afetou os moradores do Recôncavo baiano, além de revelarem iniciativas e possíveis propostas de solução para os problemas econômicos da capitania.
\end{abstract}

PALAVRAS-CHAVE: Bahia; crise econômica; Gregório de Matos; Rocha Pita.

\section{The problems of the late seventeenth century in Bahia according to the writings of Gregorio de Matos and Sebastião da Rocha Pita}

\begin{abstract}
This paper aims to study the complex economic situation faced by Bahia in the late seventeenth century and its consequences in society through documents produced by two characters who lived that moment, but in situations and with very different points of view: the poet Gregorio de Matos (1636 - 1696) and the historian Sebastião da Rocha Pita (1660 - 1738). The analysis of his writings is important in that they present readings of how the crisis affected the inhabitants of the Recôncavo of Bahia, in addition to revealing initiatives and possible proposals for solving the captaincy's economic problems.
\end{abstract}

KEYWORDS: Bahia; Economic crisis; Gregório de Matos; Rocha Pita.

\section{Los problemas de finales del siglo XVII en Bahía de acuerdo con los escritos de Gregório de Matos y Sebastião da Rocha Pita}

RESUMEN: Este artículo tiene como objetivo estudiar la compleja situación económica de Bahía en los años finales del siglo XVII y su impacto en la sociedad a través de los documentos producidos por los dos personajes que vivieron durante ese tiempo, pero en situaciones y con muy diferentes puntos de vista: el poeta Gregório de Matos (1636 - 1696) y el historiador y escritor Sebastião da Rocha Pita (1660-1738). El análisis de sus escritos es importante en la presentación de las lecturas de cómo la crisis afectó a los residentes de lo Reconcavo Baiano, y revelar posibles iniciativas y propuestas de solución a los problemas económicos de la capitanía.

PALABRAS-CLAVE: Bahía; Crisis económica; Gregório de Matos; Rocha Pita.

\footnotetext{
* Mestre em História pela Universidade Estadual Paulista "Júlio de Mesquita Filho" (UNESP) Campus Assis. Atualmente doutoranda em História pela Universidade Estadual Paulista "Júlio de Mesquita Filho" Campus Assis. Contato: Av. Dom Antônio, 2100 - Parque Universitário, CEP: 19806-900, Assis, SP, Brasil. Email: c_cintiagoncalves@hotmail.com.
} 


\section{Introdução}

Este artigo tem por finalidade analisar como o contexto de recessão da economia do final do século XVII repercutiu na vida das pessoas que habitavam o Recôncavo baiano e como foi retratada por seus contemporâneos por intermédio dos pontos de vistas contidos nos escritos de Gregório de Matos (1636 - 1696) e Sebastião da Rocha Pita (1660 - 1738), o que nos possibilita explorar as diferentes reações e propostas para uma mesma situação.

A maioria dos estudos existentes que tomam como fontes os escritos e as biografias, tanto de Gregório de Matos quanto de Sebastião da Rocha Pita, se voltam para o período literário em que estão inseridos, aos recursos estilísticos que utilizaram, ou mesmo para a contribuição deles à literatura, não havendo estudos para a questão de como o cenário em que eles viveram interferiu em suas obras.

É sobre este aspecto que o presente artigo se volta, pois estes autores retrataram a conjuntura da época ${ }^{1}$, expondo a complexa situação econômica enfrentada por Portugal e suas possessões, especificamente a Bahia, e como os problemas relacionados a esta situação, como os altos valores dos tributos pagos pela população, a baixa do preço do açúcar, o enfraquecimento do comércio, a diminuição de mão de obra escrava e a falta de dinheiro circulante, repercutiam na sociedade no final daquele século, momento em que o Reino ainda lutava por sua estabilização pós União Ibérica. Portanto, vamos analisar os problemas sob a ótica de quem, de fato, os vivenciou.

Para que tal análise seja realizada, partimos do princípio defendido por Compagnon, em sua obra de 2003, intitulada $O$ Demônio da teoria, na qual identifica o discurso histórico como uma construção social, composta de uma "multiplicidade de histórias parciais, de cronologias heterogêneas e de relatos contraditórios" e que por isso "põe em cena tanto o presente como o passado; seu texto faz parte da literatura",2.

Em virtude de compartilharmos deste pensamento de Compagnon, também se faz necessário considerarmos a relação entre a história e literatura como metodologia de estudo dos documentos a serem estudados neste artigo. Desta maneira, teremos como orientação as reflexões de Antônio Cândido apresentadas em sua obra Literatura e Sociedade, de 2000, na qual logo no prefácio o autor deixa claro que na análise de uma obra literária não podemos dissociar o social da literatura, e que "só a podemos entender fundindo texto e contexto numa interpretação dialeticamente íntegra" ${ }^{3}$. Ou seja, deve-se pensar em compreender como o contexto social influencia em uma obra literária, todavia, não se pode esquecer que a estrutura 
e a organização da mesma obra também está relacionada a um determinado padrão social específico do período em que foi produzida.

Desse modo, para que seja possível fazer uma análise mais aprofundada dos escritos dos referidos autores e assim compreender suas interpretações, se faz necessário conhecer os eventos que os circundavam.

\section{Portugal e Bahia no século XVII}

Com a restauração em 1640, Portugal passou por um período bastante delicado no qual D. João IV valeu-se de alianças diplomáticas e militares com a França, Inglaterra e Holanda para conseguir manter sua independência em relação à Espanha ${ }^{4}$. Tais acordos, porém, fizeram com que sua situação econômica, que já era crítica, se complicasse ainda mais ${ }^{5}$, uma vez que geraram aumento nos tributos pagos por todo o Reino.

No entanto, não foram somente os impostos que aumentaram: houve também o problema da concorrência da produção açucareira nas Antilhas, fazendo com que os produtos portugueses ficassem fora dos mercados franceses, ingleses e holandeses, ainda que estes carregassem açúcar e tabaco em Lisboa para vender em outras partes ${ }^{6}$. Isso levou ao acúmulo do açúcar nos armazéns e derrubada de seu montante, já que o mesmo passou a ser vendido abaixo do preço de custo ${ }^{7}$.

Segundo análise de João Adolfo Hansen às Cartas do Senado da Bahia ${ }^{8}$, no período compreendido entre 1670 e 1690, essa baixa nos valores da venda do açúcar teve muitas consequências negativas para a sociedade: refletiu diretamente no pagamento do clero e da burocracia; elevou o preço dos subsídios dos engenhos, endividou senhores, que deixaram de honrar com seus impostos e pagamento dos donativos além de aumentar a miséria da população 9 .

Em consonância com a análise de Hansen, a historiadora Vera Ferlini, em seu livro Terra, trabalho e poder, de 1988, se refere à baixa dos preços de venda do açúcar como um sério problema para o período ${ }^{10}$. Esse mesmo declínio é mostrado por Stuart Schwartz, que aponta a década de 1680 como o momento de "uma drástica baixa, com os preços do açúcar em queda enquanto os custos se elevam. A concorrência externa começou a afetar severamente o setor açucareiro no Brasil" ". A Carta do Senado da Bahia de 25 de abril de 1681 reforça esses dados, pois declara que o povo se encontrava em "ruínas e falta de cabedais causados pelo pouco rendimento e saída das drogas"12. 
Mais lamentações são encontradas no volume terceiro das Cartas do Senado 16841692, e referem-se aos altos impostos que eram pagos pelo povo e a sua decadência, consequência da elevação do valor do tributo do açúcar, de 220 para 580 réis por arroba, o qual fora decretado para auxiliar na guerra contra a Espanha e a Holanda, o que tentava assim cobrir as despesas da Companhia Geral do Comércio. Este aumento gerou mais reclamações, pois, segundo consta nas cartas, mesmo após o acordo de paz com a Holanda, nunca foram baixados ou suspensos. Desta maneira, chegou-se à conclusão de que o açúcar brasileiro não podia concorrer com os estrangeiros, pois, como não ocorreu a suspensão dos tributos, os preços não conseguiam se tornar competitivos ${ }^{13}$.

O desenvolvimento da produção açucareira nas Antilhas não prejudicou somente a posição de vendedor de açúcar das capitanias do norte do Brasil no cenário europeu, mas também influenciou no mercado de escravos, pois aumentou a demanda de mão de obra na região, fazendo com que ingleses, franceses e neerlandeses buscassem fontes seguras de cativos na costa da África, o que gerou, consequentemente, concorrência, e prejudicou o fornecimento de mão de obra escrava para a América Portuguesa.

Assim, ao aumentar o preço dos cativos, ampliavam-se as despesas dos senhores de engenho, a exemplo da Carta do Senado da Bahia, de 1 de dezembro de 1674, na qual os senhores pediam que fosse proibido o embarque de negros trazidos de Angola para a Bahia em direção ao Reino, pois, segundo eles, só existiam servidores negros de Angola e eram em tão pouco número que não supriam as necessidades das fábricas, e, assim, perdiam muito lucro $^{14}$.

\section{Adversidades cotidianas}

Gregório de Matos Guerra nasceu na Bahia em 1633, e faleceu em 1696. Descendente de uma família opulenta, estudou no colégio dos jesuítas de Salvador, e, em 1662, formou-se pela Universidade de Coimbra. No ano seguinte, em 1663, foi nomeado juiz de fora de Alcácer do Sal (Alentejo) ${ }^{15}$. Ocupou vários cargos importantes na Corte e, em 1682, um ano após retornar à Bahia, foi nomeado para funções na burocracia eclesiástica da Sé da Bahia, cargo que ocupou por pouco tempo por não querer usar batina e não aceitar a imposição de ordens maiores. Após tal acontecimento, passou a satirizar os costumes dos diferentes seguimentos políticos e estamentais da Bahia, ${ }^{16}$ o que lhe rendeu a alcunha de Boca do Inferno. 
Devido aos seus poemas, recebeu várias acusações e, correndo o risco de ser assassinado, foi enviado para Angola em 1694. Como forma de recompensa por ajudar o governo local no combate a uma conspiração militar, em 1695 recebeu autorização para retornar a América Portuguesa, desde que cumprisse duas condições: não fazer mais sátiras e não se estabelecer novamente na Bahia. Em virtude dessas exigências, acabou por fixar residência na cidade de Recife $^{17}$.

Gregório de Matos encontrou nos seus poemas uma maneira de denunciar as mazelas que ocorriam na Bahia e apesar de não propor nenhuma solução prática para tais problemas, acabava por deixar claro aos responsáveis pelo poder, onde estavam os impasses que necessitavam de alguma atitude. Segundo estudo de Hansen, uma explicação para tal comportamento do poeta poderia ser a ideia de que "a sátira é guerra caritativa: fere para curar" $^{\prime 18}$, ou seja, apontando-se os erros, esses poderiam ser solucionados.

Apesar de ser brasílico, o poeta apresentava uma visão da aristocracia de Portugal, pois, além de ter vivido grande parte de sua vida no Reino e prestado serviços para a Coroa, fazia parte de uma nobreza que estava perdendo seu espaço de poder com a redefinição da economia mercantilista. Tinha, assim, uma visão conservadora e moralista da sociedade da América Portuguesa, como podemos perceber pela abordagem do poeta sobre a vida na Bahia, que estava em transformação e que sempre era comparada com seu passado e com a situação de Portugal ${ }^{19}$.

Em vista disso, para obter uma melhor compreensão do que ocorria na sociedade em que Gregório de Matos estava inserido, se faz necessário termos acesso a outros escritos, de indivíduos que vivenciaram também tal momento. Em virtude de oferecer outra perspectiva sobre a mesma conjuntura e por apresentar uma leitura de natureza histórica da complexa sociedade estabelecida na América portuguesa, a obra de Sebastião da Rocha Pita História da América Portuguesa também foi selecionada para compor este estudo.

Sebastião da Rocha Pita nasceu na cidade de Salvador, em 3 de maio de 1660, e faleceu em 2 de novembro de 1738, também na Bahia. Estudou no colégio dos jesuítas e graduou-se mestre em Artes. Na universidade de Coimbra, obteve o grau de Bacharel em Cânones. Foi coronel do Regimento privilegiado de ordenanças - título atribuído a pessoas importantes pelo respeito social, pela fortuna e pela ascendência. Também foi fidalgo da casa real, cavaleiro da Ordem de Cristo, acadêmico supranumerário da Academia Real de História Portuguesa e membro da Academia Brasílica dos Esquecidos ${ }^{20}$.

Mesmo sendo contemporâneos e compartilhando de uma posição muito semelhante ao que se refere à proximidade com a Coroa, os autores aqui analisados apresentavam pontos de 
vista e posições bastante diferentes. Enquanto Gregório de Matos denunciou diretamente em vários de seus poemas os infortúnios da América Portuguesa e principalmente da capitania da Bahia; Rocha Pita procurou descrever a mesma conjuntura de modo a não emitir julgamento direto, sempre se referindo às fontes utilizadas, sejam documentos oficiais ou relatos da cultura popular. Esse fato favoreceu a publicação de seu livro História da América Portuguesa "com todas as licenças necessárias", como aparece na folha de rosto da obra ${ }^{21}$.

Nos poemas de Gregório de Matos é possível perceber sua preocupação em mostrar a situação complicada que a Bahia atravessava, visto que, como afirma Alfredo Bosi em Dialética da colonização (1992), o poeta foi um “observador in loco" desta conjuntura, desde a formação e enriquecimento de uma "pequena nobreza luso-baiana” até sua ruína ${ }^{22}$. Por essa razão, em vários momentos comparou seu passado farto com o complexo presente.

Diante disso, argumentou que o povo da Bahia encontrava-se na miséria, consequência do alto valor dos tributos, dos produtos de necessidade básica, que além de caros, muitas vezes faltavam, pois eram enviados pelas frotas para Portugal. Contudo, não denunciou somente a penúria do povo, mas também indicou os possíveis responsáveis que contribuíram para se chegar a tal situação.

Nesse sentido, o primeiro responsável mencionado por Gregório de Matos para que a capitania da Bahia estivesse na situação delicada em que se encontrava foi a Câmara, que mesmo ciente de todo o problema nada fazia, pois não era afetada diretamente e vivia em uma situação de fartura. Além da Câmara, as frotas também eram vistas pelo poeta como culpadas pela preocupante situação, pois se abarrotavam de produtos e os levavam embora, deixando a população às minguas:

\footnotetext{
a Câmara, outros a frota; a frota tudo abarrota dentro dos escotilhões, a carne, o peixe, os feijões; e se a Câmara olha e ri, porque está farta até aqui, é coisa que me não toca: Ponto em boca. ${ }^{23}$
}

O sistema de frotas foi adotado por Portugal, principalmente após a Restauração, para proteger seu comércio colonial em virtude dos conflitos com a Espanha, com a Holanda e mesmo com a Inglaterra, o qual proibia viagens isoladas, sobretudo, a partir de $1660^{24}$. Eram bastante importantes para os moradores da América Portuguesa e para o Reino, pois, além de proteger o comércio marítimo, traziam notícias da Europa, correspondências e estimulava o comércio local com os novos produtos que chegavam. ${ }^{25}$ 
Mesmo com estes pontos positivos, a quinta estrofe do poema conhecido por "Agora com a experiência dos males, que padece a República nestas alterações, se jacta de o haver estranhado então: julgando por causa total os ambiciosos estrangeiros inimigos dos bens alheios", mais uma vez, apresenta uma referência negativa às frotas e ao comércio:

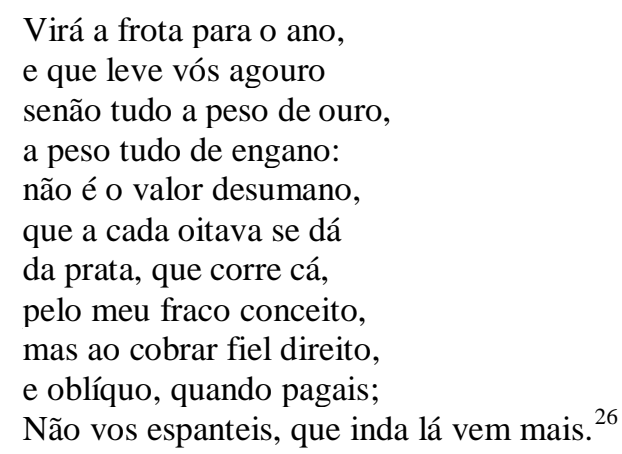

Conforme se percebe no início da estrofe, os produtos transportados pelas frotas, como, por exemplo: vinho, azeite, vinagre, aguardente, presuntos, chouriços, manteiga, queijos, açúcar refinado, pimenta, farinha de trigo, chumbo, peças de cobre e estanho, facas, objetos de louças e vidro, papel, cera, roupas ${ }^{27}$, eram comercializados por um preço mais alto, podendo ser adulterados, o que resultava no enfraquecimento do comércio.

A posição pessimista do autor continua ao se referir, no quinto verso, ao dinheiro que já era pouco e acabava sendo levado pelos comerciantes para Portugal, prejudicando as posteriores negociações comerciais locais. Diante de tal conjuntura, nos mostra não esperar por uma melhora na situação econômica, como se nota no último verso: "Não vos espanteis, que inda lá vem mais".

$\mathrm{Na}$ última estrofe, a seguir, a persona satírica parece desapontada com a situação, e, além de repetir seu refrão, enfatizando que não possuía expectativas de melhoras, assevera que o estado complicado em que se encontravam era merecido, pois os baianos nada faziam para melhorar, só ficando esperando novas frotas, com talvez novas notícias ou soluções:

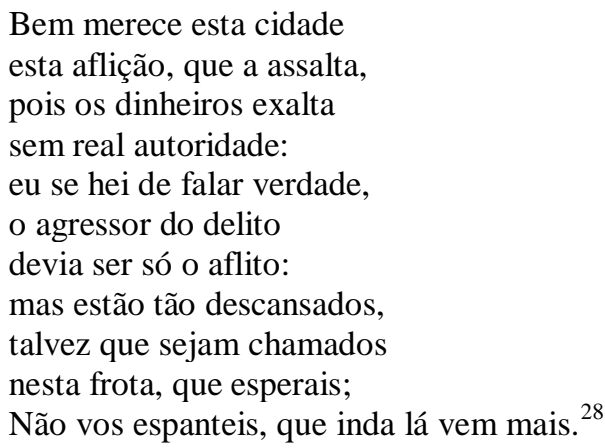


Já Sebastião da Rocha Pita, para explicar a mesma situação, partiu da estabilidade e riqueza da América Portuguesa, especialmente da Bahia, mostrando as boas características antes da crise, referindo-se à boa produção de açúcar, ao grande número de engenhos e de embarcações que chegavam e saíam dos portos, bem como a variedade de mercadorias ofertadas:

\begin{abstract}
O seu recôncavo é tão culto e povoado, que se lhe descrevêramos as fábricas e lhe numeráramos os vizinhos, gastaríamos muitas páginas e não poucos algarismos; (...) existem cento e cinquenta engenhos, (...) fazendo a cada ano e um por outro, quinze e dezesseis mil caixas de açúcar de muitas arrobas cada uma (...). Há varias fazendas de cana, algumas tão grandes na extensão e pela bondade do terreno tão fecundas, que rendem dois mil e dois mil e quinhentos pães, dos quais a metade fica aos senhores de engenho que as moem e beneficiam o açúcar. [...] O comércio que lhe resulta dos seus preciosos géneros e da frequência das embarcações dos portos do Reino, das outras conquistas, e das mesmas províncias do Brasil trocando umas por outras drogas, e faz uma feira de todas as mercadorias, um empório de todas as riquezas $^{29}$.
\end{abstract}

Pelo excerto se nota o quanto a Bahia era rica, com altos números na produção e no comércio, o que gerava elevadas receitas. Diferente de Gregório de Matos, Rocha Pita não fez críticas ao comércio e às frotas que por ali chegavam. No entanto, mais adiante, evidencia que a situação inicial de prosperidade se transformou e o que antes era opulência começou a passar por dificuldades, como é o caso dos engenhos e da produção de açúcar, consequência da elevação do "valor dos géneros de que pendem todas as suas fábricas" além dos "acidentes do tempo" que acabavam por prejudicar a produção e mais uma vez diminuir a renda dos proprietários $^{30}$.

Além das complicações na produção de açúcar, o autor elencou outros motivos que levaram a população a alcançar esta posição econômica pouco confortável, como a carestia de vida, haja vista que "o preço dos víveres" crescia "com a multidão dos moradores"; o gasto com "luxo e a prodigalidade [...] de suas riquezas, sendo mais fáceis em despendê-las que em adquiri-las", para tentar manter o padrão inicial de vida, que gerava endividamento e, consequentemente, seu empobrecimento, pois "acham muitos com moderados bens, poucos com cabedais excessivos; uns não se devem ter por pobres, outros não se podem chamar opulentos" $" 31$.

As explicações para a situação de recessão da economia não pararam por aí, pois, assim como Gregório de Matos, Rocha Pita se preocupava em mostrar as origens do problema. Para isso, se remeteu também à questão da tributação, responsável, segundo o autor, pelo endividamento da América Portuguesa, principalmente no que se referia ao pagamento dos impostos, como o da Paz de Holanda e o do dote de Inglaterra, os quais foram 
repartidos "por todas as províncias do Brasil os cento e vinte mil cruzados que se lançavam em cada um dos dezesseis anos sobre este Estado". Salientou, todavia, que a maior parte ficou sob a responsabilidade da "Bahia, como cabeça da portuguesa América [...], que foram oitenta mil cruzados", os outros sessenta mil cruzados foram divididos "pelas outras treze províncias", o que totalizaria, no final dos dezesseis anos "dois milhões e duzentos e quarenta mil cruzados" 32 .

A Ata da Câmara de Salvador, de 17 de maio de 1662, confirma o valor de oitenta mil cruzados de contribuição do dote e paz como responsabilidade da capitania da Bahia, conforme Rocha Pita apresentou, e também detalha, igualmente, os valores exatos das outras $\operatorname{capitanias}^{33}$.

Em 20 de dezembro de 1677, quando Dom Pedro, príncipe regente, preocupado com os prejuízos nas remessas que eram enviadas ao Reino, baixou um regimento com novos valores referentes à "Cobrança dos donativos do dote de Inglaterra e paz de Holanda e dinheiro da obra pia" a situação não mudou muito para a Bahia. A capitania continuou com a maior parte do ônus: "quarenta e dois mil, seiscentos e sessenta e seis cruzados e meio", enquanto Pernambuco ficou incumbido de recolher vinte mil, o Rio de Janeiro dezenove mil, trezentos e trinta e três e Angola dez mil cruzados ${ }^{34}$.

Caso os indivíduos não conseguissem manter em dia seus débitos, seriam sentenciados na "Relação da Bahia com os adjuntos que o governador vos nomear". Já nas capitanias de Pernambuco e Rio de Janeiro seriam atendidos pelo ouvidor ${ }^{35}$. Assim, ninguém estava isento de contribuir com os donativos, e isso gerava inúmeras reclamações presentes nas cartas enviadas a Câmara de Salvador. Tais documentos apresentam as mais diversas alegações, desde pedidos de prolongamento de prazos para o pagamento até a dispensa do mesmo por não se ter nenhuma condição de realizá-lo.

O quadro da saúde na Bahia descrito por Rocha Pita também não era dos melhores devido o surto "das bexigas" ${ }^{\text {" }}$ que se alastrou rapidamente entre as pessoas, a ponto de em uma família não haver uma pessoa sã "que pudesse curar das enfermas, nem sair a buscar os remédios e chamar os médicos" ${ }^{37}$ e ocasionou a falta de remédios e de médicos para tratar das enfermidades. Este quadro teve reflexos diretos na economia, resultando na falência de fazendeiros que, sem mão de obra, não conseguiam levar a diante suas lavouras e "perdendo todos os que tinham, [...] não puderam em sua vida tornar a beneficiar suas possessões" 38 .

O autor também não deixou de abordar a epidemia do "mal da bicha", que começou na capitania de Pernambuco, mas acabou se alastrando para a Bahia e igualmente assolou a população, contribuindo para a ruína da sociedade no ano $1686^{39}$. 
Preocupação semelhante à de Rocha Pita no que se refere à proliferação das doenças e a sua consequente perda de mão-de-obra escrava pode ser encontrada nos documentos oficiais do período, como por exemplo, nas Atas da Câmara de Salvador. Em Ata datada de 21 de maio de 1685, a Câmara assentou a "vistoria e resolução que se tomou sobre a chegada da nau Santa Marta vinda de Angola com os negros com bexiga", na qual o médico Manoel de Mattos, após examinar a situação a bordo do navio, requereu baseado em outros surtos de bexiga anteriores e seus prejuízos, que colocassem a nau em quarentena, "a mais de quatro léguas" da cidade. Também foi solicitado que não se desembarcasse nenhum escravo e comunicassem "todas as vilas e seu recôncavo". Desse modo, evitariam a mortandade, além da falência de engenhos e fazendas, como já haviam presenciado em outras situações ${ }^{40}$.

Não eram diferentes as ações vinculadas aos navios que transportavam cativos contaminados com o "mal da bicha", como é possível observar na Ata de 27 de janeiro de 1694, referente a um navio que veio da Costa da Mina. Devido ao contágio, o navio ficou de quarentena na "ilha de Itaparica, no sítio que chamam de Manguinho". O temor de que a doença se espalhasse e que, junto com ela, os danos financeiros crescessem, fez com que a Câmara iniciasse o referido documento estabelecendo que "se evitassem todos os navios, especialmente os que vinham de Angola, São Tomé e Costa da Mina" com o objetivo de evitarem as patologias que prejudicariam a cidade, como já havia acontecido antes com outras embarcações vindas dos mesmos lugares.

O segundo ponto da Ata narra a visita do médico Manoel de Mattos ao navio e seu parecer, o qual mandava "pelo bem público desta cidade" que não se desembarcassem as pessoas que vinham nesta embarcação, "por vir muitas delas danificadas". Além disso, o próprio capitão afirmou que já haviam morrido "quinze ou dezesseis negros, fora outros que se mataram por quererem alevantar". Diante desta situação, o médico colocou o barco em quarentena, mas foi questionado pelo próprio capitão, João Godinho da Maia, que através de uma segunda petição logo indeferida, solicitava uma nova vistoria navio com o intuito dos negros serem logo desembarcados ${ }^{41}$ e assim conseguir o retorno do investimento de viagem com a venda destes.

Tanto nos documentos da Câmara quanto nas descrições de Rocha Pita, a falta de mão-de-obra escrava era uma grande preocupação para a capitania da Bahia, pois impactava diretamente na diminuição da produção e também dos lucros. E, mesmo com estudos que mostram o elevado número de africanos, especificamente angolanos, desembarcados nas Américas, como é o caso da obra $O$ trato dos viventes (2000), de Luiz Felipe de Alencastro, é possível notar que no período abordado por este artigo ocorreu certa diminuição no fluxo. 
Enquanto entre 1651-1675 desembarcavam no Brasil 185.000 africanos, no período seguinte, de 1676 a 1700 , esse número caiu para $175.000^{42}$.

Este decréscimo na entrada de cativos somado às mortes causadas pelas doenças acima citadas e ao deslocamento para outras capitanias e para o Reino, levou os camarários de Salvador a solicitarem junto à Coroa que não deixasse embarcar para Portugal os negros de Angola que ali estavam, pois se perdia muito lucro, uma vez que não se supria a demanda de mão-de-obra das fábricas, conforme a Carta do Senado de 1 de dezembro de $1674^{43}$.

Insta salientar que a questão da circulação de moedas não passou despercebida pelos olhares dos autores. Enquanto Gregório de Matos condenava as atitudes tomadas em relação ao numerário para se recuperar a economia, Rocha Pita procurou descrever todo o problema, inclusive, as iniciativas da Câmara de Salvador para tentar sair deste impasse.

A desaprovação do poeta em relação à desvalorização monetária pode ser notada na estrofe a seguir:

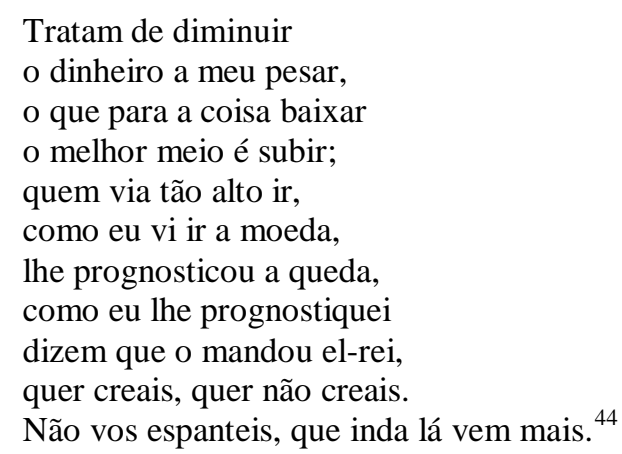

Acima, a persona satírica inicia o poema demonstrando desapontamento ao falar da desvalorização da moeda, pois, com a situação nada favorável da Bahia, como também aparece no poema analisado anteriormente, somente os exportadores de açúcar seriam favorecidos com tal medida, enquanto o restante da população, que não dependia de exportações, não teria nenhum benefício e acabariam por empobrecer com tal medida.

Ao se referir à figura do rei, é possível perceber um tom de descontentamento com tal ação e até de descrença em tal ordem que tanto prejudicaria o povo. Ainda, terminando a estrofe, o verso usado como refrão demonstra a incredulidade quanto à melhora da situação enfrentada, como se não houvesse uma maneira de melhorar os males da economia baiana.

As estrofes seguintes expõem que a desvalorização não foi o único problema relacionado ao dinheiro circulante: 


\author{
Manda-o a força do fado, \\ por ser justo, que o dinheiro \\ baixe a seu valor primeiro \\ depois de tão levantado: \\ o que se vir sublimado \\ por ter mais quatro mangavas, \\ hão de pesá-lo as oitavas, \\ e por leve hão de enjeitá-lo: \\ e se com todo este abalo \\ por descontentes vos dais, \\ Não vos espanteis, que inda lá vem mais. \\ As pessoas, que quem rezo, \\ hão de ser como o ferrolho, \\ val pouco tomado a olho, \\ val menos tomado a peso: \\ os que prezo, e que desprezo \\ todos serão de uma casta, \\ e só moços de canastra \\ entre veras, e entre chanças \\ com pesos, e com balanças \\ vão a justiçar os mais: \\ Não vos espanteis, que inda lá vem mais. ${ }^{45}$
}

Seguindo com as denúncias, o eu lírico se remete ao fato de que as moedas, além de desvalorizadas, também estavam sendo cerceadas, o que acarretaria em sua recusa caso fossem pesadas, pois estariam mais leves que o esperado e não corresponderiam ao seu correto valor. E complementa, na estrofe, que o numerário em poder da população já valia pouco devido a sua aparência, entretanto, se fosse pesado, perceberia que valia muito menos. Desanimado perante tal situação, repete o refrão: "Não vos espanteis, que inda lá vem mais".

$\mathrm{Na}$ quarta estrofe, ao retratar a crise na circulação das moedas, aponta para a situação do Maranhão, a qual a falta do numerário era tão grande que usavam, para realizar pagamentos, novelos de algodão. Na Bahia, segundo o poeta, não seria diferente, o que ocasionaria um retrocesso, pois seria necessário que retomassem as atividades de escambo, como no início "das gentes", ou seja, regredindo nas maneiras de se comercializar:

\author{
Porque como em Maranhão \\ mandam novelos à praça, \\ assim vós por esta traça \\ mandareis o algodão: \\ haverá permutação, \\ como ao princípio das gentes, \\ e todos os contraentes \\ trocarão droga por droga, \\ pão por sal, lenha por soga, \\ vinhas por canaviais: \\ Não vos espanteis, que inda lá vem mais. ${ }^{46}$
}


Sebastião da Rocha Pita, por sua vez, apresentou o problema e as soluções encontradas para questão do cerceamento das moedas de prata, sua fundição e envio para o Reino. Sobre o cerceamento, revelou que após "muito tempo" e "vários danos na moeda", foram "punidas algumas pessoas", outras em que houve "indícios de cúmplices, e outras em que por não haver provas suficientes, não tiveram todo o castigo que mereciam, a serem convictos como réus". Diante de tal problema, a solução inicial foi aplicar detalhes nas moedas, neste caso, um serrilhado em seu entorno ${ }^{47}$.

Sobre a fundição das moedas, descreveu detalhadamente o processo de fraude, no qual "as pessoas as mandavam converter em baixelas para o seu uso, e os ourives as fundiam para suas obras", sem se preocuparem com as consequências. Isso contribuía ainda mais para a diminuição do dinheiro circulante, acabando por enfraquecer a "nossa América", pois, os impérios sem moeda "são cadáveres, vindo a faltar o trato e o comércio que sustentam as monarquias" ${ }^{48}$.

Discurso semelhante é encontrado no "Treslado do requerimento que fez o Juiz do Povo e Mesteres sobre a moeda e prata feito aos 11 de fevereiro", no qual os requerentes condenavam a atitude dos ourives de fundir as moedas, afirmando que tal atitude era inclusive pior que a dos mercadores "pois aquele que foi pode voltar e a moeda que se converte em baixelas e diferentes usos extraordinários nunca mais torna ser moeda, delito que não tem desculpa", uma vez que gerava grandes prejuízos "aos negócios" e a população ${ }^{49}$.

Ante a descrição de Rocha Pita e o Treslado acima, é notável o transtorno que a atitude dos aurífices gerou na Bahia, sobretudo, se considerarmos que o documento ainda segue solicitando que os camarários pedissem ao capitão-geral punições a todos os envolvidos no processo de fundição e extravio da prata lavrada para a Angola ${ }^{50}$.

Retomando a questão do cerceamento, Rocha Pita assim como Gregório de Matos, se referiu à questão do peso do numerário e relatou que tal procedimento, além de causar a desvalorização do dinheiro, atrasava negociações, pois, havendo muitas moedas com "menos peso dos setecentos e cinquenta, era preciso para se receberem, trazerem-se balanças em que se pesassem, gastando-se muito espaço de tempo para se contar pouca quantia de dinheiro"51.

Após apresentar os reveses causados pelo cerceamento e fundição das moedas, bem como suas consequências para a América Portuguesa, Rocha Pita não deixou de apresentar a tentativa de solução do Senado da Câmara para tal problema, que recorreu ao rei D. Pedro II solicitando que fosse autorizado "a tempo que ainda pudesse remediar-se a ruína, e antes que se acabasse de consumir a moeda, mandando para Bahia Casa em que ela se lavrasse provincial para correr só no Brasil’"52. 
Todavia, como consta na carta de 24 de julho de 1680, a proposta para a criação da moeda local não era recente, pois desde 16 de agosto de 1678 a Câmara já enviava cartas para o Reino, mas não conseguia obter uma resposta positiva ${ }^{53}$. O tão aguardado retorno só veio em 08 de março de 1694 quando o rei consentiu a fundação da Casa da Moeda provincial na Bahia $^{54}$. Seu objetivo, porém, não somente de sanar o problema da escassez de dinheiro que tanto prejudicava o comércio e a população da capitania da Bahia, como mostraram Rocha Pita, Gregório de Matos, as Atas da Câmara e as Cartas do Senado, mas também de retomar as contribuições e impostos reais que igualmente haviam diminuído.

\section{Considerações finais}

O propósito deste artigo foi mostrar como a crise econômica do final do século XVII afetou a capitania da Bahia e influenciou nos escritos de Gregório de Matos e Sebastião da Rocha Pita, pessoas que viveram esta situação, analisando e comparando seus pontos de vista e posições sobre tal realidade.

Apesar dos excessos nas descrições da situação vivenciada pela população, uma característica do recurso estilístico do período, a documentação produzida possibilita verificar que o quadro econômico já deficitário devido os altos impostos pagos pela população da capitania da Bahia, consequência dos acordos realizados por Portugal para sua independência em relação à Espanha, se agravou ainda mais com a concorrência antilhana, o que levou à derrubada nos preços de venda do açúcar e, consequentemente, seu acúmulo nos armazéns, desencadeando várias outras complicações, como o aumento nos subsídios necessários para a produção do açúcar; o encarecimento e muitas vezes falta de mão-de-obra escrava destinada não só a trabalhos na lavoura de cana e no engenho, mas a outros setores da agricultura; o endividamento e falência dos senhores, que, com a diminuição do valor e da venda do açúcar, não conseguiam sanar suas dívidas e impostos, prejudicando o comércio local e seu abastecimento.

Foi neste contexto de atribulações que os dois autores analisados neste artigo viveram e escreveram seus textos. Todavia, se remeteram a estas circunstâncias de modos distintos, pois, enquanto Gregório de Matos foi rigoroso em suas críticas, não poupando instituições ou pessoas que ele acreditava serem responsáveis pelas desventuras da capitania da Bahia; Rocha Pita foi mais ponderado ao se referir às mesmas circunstâncias, sempre procurando apresentar os problemas, acompanhados de suas possíveis justificativas, causas e possíveis tentativas de 
soluções, além de identificar responsáveis apresentados por documentos oficiais ou por relatos da população.

Tal diferença de comportamento pode ser explicada pelos momentos que viveram durante a crise, pois, enquanto Gregório de Matos fez parte da formação e do auge de uma "pequena nobreza luso-baiana",55 que se desenvolveu junto com os engenhos no início do século XVII, mas que também sofreu com os efeitos da recessão do final do século, sentindo na pele seus efeitos e escrevendo no calor do momento; Sebastião da Rocha Pita nasceu quando a crise se iniciava e cresceu durante seu desenrolar, o que permitiu a ele um olhar diferente, além da possibilidade de escrever em uma conjuntura em que já existiam ações e documentos que tentavam encontrar soluções para o problema. Ainda, quanto aos objetivos das análises de ambos os autores, enquanto Gregório de Matos denunciava às autoridades onde estavam os problemas, independente do ambiente ou da situação para que talvez pudessem tomar alguma atitude, Rocha Pita procurou traçar um panorama geral da situação, mostrando os problemas e também as possíveis saídas utilizadas naquele momento.

Portanto, partindo da vivência de cada autor, ambos descreveram detalhadamente a conjuntura em que se encontrava a sociedade baiana, e, mesmo com objetivos distintos e exageros linguísticos, muitas vezes utilizados não somente para descrever o contexto, como também para tentar alcançar seus propósitos, pode-se perceber que a preocupação dos autores foi bastante semelhante nos fragmentos apresentados nesse trabalho: a de pensar a complexa situação econômica da capitania da Bahia, compreendê-la e, dentro das possibilidades de cada um, encontrar uma forma melhorar a situação: seja mostrando as falhas para os que estivessem no poder pudessem tomar a iniciativa e corrigi-las, ou, descrevendo detalhadamente toda a situação junto com as atitudes que já haviam sido tomadas, permitir que se pensasse novas propostas de intervenção ou mesmo de solução para os impasses.

\section{NOTAS:}

\footnotetext{
${ }^{1}$ Sobre a questão da crise do século XVII conferir: FERLINI, Vera Lúcia A. Terra, trabalho e poder. São Paulo: Brasiliense; 1988; FRAGOSO, João; BICALHO, Maria Fernanda; GOUVÊA, Maria de Fátima (orgs.). $O$ Antigo Regime nos Trópicos: a dinâmica imperial portuguesa (séculos XVI-XVIII). Rio de Janeiro: Civilização Brasileira, 2001. FREITAS, Gustavo de Freitas. A Companhia Geral do Comércio do Brasil (1649-1720): subsídios para a História Econômica de Portugal e do Brasil. São Paulo: Coleção da Revista de História, 1951. GODINHO, Vitorino de Magalhaes. “1580 e a Restauração”. IN: ENSAIOS. Lisboa: Sá da Costa; 1968. NOVAIS, Fernando. Portugal e Brasil na Crise do Antigo Sistema Colonial (1777-1808). São Paulo: Hucitec, 1979. SALLES, Wesley D. Tempos de Crise: O império português, a crise açucareira, o tráfico de escravos e a lei das arqueações (1640 - 1695). 2014. 251f. Dissertação (Mestrado em História). - Faculdade de Ciências e Letras, Universidade Estadual Paulista - Júlio de Mesquita Filho, Assis, 2014; SCHWARTZ, Stuart B. Segredos internos: engenhos e escravos na sociedade colonial, 1550-1835. São Paulo: Companhia das Letras, 1995. Sobre
} 
a crise que se abatera sobre a Bahia na segunda metade do século XVII ver: GOMES, Cintia Goncalves. Senhora Dona Bahia: um estudo sobre a crise do século XVII. 2014. 120 f. Dissertação (Mestrado em História). Faculdade de Ciências e Letras, Universidade Estadual Paulista "Júlio de Mesquita Filho", Assis, 2014.

${ }^{2}$ COMPAGNON, Antoine. O demônio da teoria: literatura e senso comum. Tradução de Cleonice P. B. Mourão, Consuelo Fortes Santiago. Belo Horizonte: Ed. UFMG, 2003. p. 202.

${ }^{3}$ CANDIDO, Antonio. Literatura e sociedade. 8 ed. São Paulo: T. A. Queiroz, 2000. p. 6.

${ }^{4}$ AZEVEDO, J. Lúcio de. Épocas de Portugal Económico: Esboços de História. 2a edição. Lisboa: Livraria Clássica Editora, 1947. p. 386-388.

${ }^{5}$ SCHWARTZ, Stuart B. Segredos Internos: engenhos e escravos na sociedade colonial, 1550-1835. São Paulo: Companhia das Letras, 1995. p.164.

${ }^{6}$ MARCADÉ, Jacques. O quadro internacional e imperial. In: MAURO, In: SERRÃO, Joel; MARQUES, A. H. de Oliveira (direcção). Nova história da Expansão Portuguesa. Vol. VII. Lisboa: Estampa, 1991. p. 36.

${ }^{7}$ GODINHO, Vitorino de Magalhaes. 1580 e a Restauração. IN: Ensaios. Lisboa: Sá da Costa, 1968. p. 483.

${ }^{8}$ Cópias das Cartas do Senado e das Atas da Câmara da Bahia foram publicadas pela Prefeitura de Salvador entre os anos de 1949 e 1959, mantendo a ordem cronológica e a grafia original do século XVII, sendo quatro volumes das Cartas e seis volumes das Atas. São documentos importantes para o estudo do século XVII, pois através deles é possível ter contato com as representações e acontecimentos relevantes do período, pois enquanto as Atas descrevem ações sobre as quais a Câmara deliberou, as Cartas se referem a situações do cotidiano do povo, geralmente pedidos e negociações do Senado da Câmara junto à Coroa.

${ }^{2}$ HANSEN, João Adolfo. A sátira e o engenho: Gregório de Matos e a Bahia do século XVII. São Paulo: Companhia das Letras; Secretaria de Estado da Cultura, 1989. p. 109.

${ }^{10}$ FERLINI, Vera Lúcia A. Terra, trabalho e poder. São Paulo: Brasiliense; 1988, p. 70-71.

11 SCHWARTZ, Stuart B. Segredos Internos. Op. cit. p. 147.

12 Documentos Históricos do Arquivo Municipal da Bahia. Cartas do Senado 1673-1684. $2^{\circ}$ Volume. Salvador: Prefeitura do Município de Salvador-Bahia, 1952. p. 93-94.

${ }^{13}$ Documentos Históricos do Arquivo Municipal da Bahia. Cartas do Senado: 1684- 1692. $3^{\circ}$ Volume. Salvador: Prefeitura do Município de Salvador-Bahia, 1953. p. 70-72.

${ }^{14}$ Documentos Históricos do Arquivo Municipal da Bahia. Cartas do Senado 1673-1684. Op. cit. p. 21.

${ }^{15}$ SPINA, Segismundo. A poesia de Gregório de Matos. São Paulo: USP, 1995. p. 18.

${ }^{16}$ RABELO, Manuel Pereira. Vida e Morte do Doutor Gregorio de Mattos e Guerra, Escrita pelo Licenciado Manuel Pereyra Rabello. In: GUERRA, Gregorio de Matos e. Obras Sacras e Divinas. Tomo I, I e II parte. Cofre 50, Códice 56, Seção de manuscritos da Biblioteca Nacional do Rio de Janeiro, p. 1699-1702.

${ }^{17}$ PERES, Fernando da Rocha. Gregório de Matos: o poeta devorador. Rio de Janeiro: Manati, 2004. p. 118.

${ }^{18}$ HANSEN, João Adolfo. A sátira e o engenho. Op. cit. p. 28.

${ }^{19}$ Sobre as transformações ocorridas na Bahia no século XVII ver: BOSI, Alfredo. Do antigo estado à máquina mercante. In: Dialética da colonização. São Paulo: Companhia das Letras, 1992. p.94-118.

${ }^{20}$ BLAKE, Augusto Victorino Alves Sacramento. Diccionario bibliographico brasileiro. Rio de Janeiro: Conselho Federal de Cultura, 1970. v. 7. p. 214. Disponível em: <http://www.brasiliana.usp.br/handle/ 1918/00295770>. Acesso em: 15 nov. 2015.

${ }^{21}$ PITA, Sebastião da Rocha. História da América Portuguesa. Lisboa: Officina de Joseph Antonio da Sylva Impressor da Academia Real, 1730. Na parte "Licenças" logo no início da obra, existem dois pareceres favoráveis à sua publicação: o primeiro é da Academia Real, feita por Antônio Rodrigues da Costa e o segundo é do qualificador do Santo Ofício, Antônio Caetano de Souza.

${ }^{22}$ BOSI, Alfredo. Dialética da colonização. São Paulo: Companhia das Letras, 1992. p. 98-99.

${ }^{23}$ MATOS, Gregório de. Crônica do viver baiano seiscentista. Organização de James Amado. Bahia: Janaína, 1990. p. 339.

${ }^{24}$ HUTTER, Lucy Maffei. Navegação nos séculos XVII e XVIII: rumo: Brasil. EdUSP, 2005. p. 85.

25 MAURO, Frédéric. Portugal, Brasil e o Atlântico. 1570 - 1670. Tradução Manuela Barreto. Editorial Estampa, 1988. p. 201-211.

${ }^{26}$ MATOS, Gregório de. Crônica do viver baiano seiscentista. Op. cit. p. 342.

${ }^{27}$ HUTTER, Lucy Maffei. Op. cit. p. 141

${ }^{28}$ Idem.

${ }^{29}$ PITA, Sebastião da Rocha. Op. cit. p. 61-62.

${ }^{30}$ Ibidem. p. 107.

${ }^{31}$ Idem. p. 107.

32 Ibidem. p. 267.

${ }^{33}$ Resolução que se tomou perante o Senhor Francisco Barreto governador deste Estado sobre a contribuição do dote da Senhora Rainha da Grã-Bretanha e Paz de Holanda, de 17 de maio de 1662. In: Atas da Câmara 16591669. Documentos Históricos do Arquivo Municipal da Bahia. $4^{\circ}$ vol. 1949. p.136-140. 
34 Documento disponível em: http:<//memoria.bn.br/pdf/094536/per094536_1945_00067.pdf>, acesso em 01/10/2016 - p. 236. Além da Carta Régia que dispõe sobre os valores a serem pagos por capitania, o documento também possui uma carta do príncipe regente a Roque da Costa Barreto e Bernardo Vieira Ravasco solicitando que nomeiem ministros com o objetivo de fazer a correta arrecadação de tal tributo.

35 Idem.

${ }^{36}$ Segundo Raphael Bluteau: "Doença conhecida que cobre o couro de bolhas. Procede de um sangue viciado que causa essa efervescência na massa sanguínea. É altamente contagioso." BLUTEAU, Raphael. Vocabulario Portuguez e Latino. Coimbra: Collegio das Artes da Companhia de Jesus, 1712-1728. vol. 2. p. 115.

${ }^{37}$ PITA, Sebastião da Rocha. Op. cit. p. 273.

${ }^{38}$ Ibidem. p. 275.

${ }^{39}$ Ibidem. p. 322.

${ }^{40}$ Ata de 21 de maio de 1685. In: Atas da Câmara 1684-1700. Documentos Históricos do Arquivo Municipal da Bahia. $6^{\circ}$ vol. 1951. p. 22-23.

${ }^{41}$ Ata de 27de janeiro de 1694. Ibidem. p. 237-238.

42 Tabela I.I - Desembarque de africanos nas Américas. In: ALENCASTRO, Luis Felipe de. $O$ trato dos viventes. Formação do Brasil no Atlântico sul. São Paulo: Companhia das Letras, 2000. p. 389.

${ }^{43}$ Carta de 01 de dezembro 1674. In: Cartas do Senado 1673-1684. Op. cit. p. 21.

${ }^{44}$ Retratado no poema: "Agora com a experiência dos males, que padece a República nestas alterações, se jacta de o haver estranhado então: julgando por causa total os ambiciosos estrangeiros inimigos dos bens alheios" In: MATOS, Gregório de. Obra poética. Rio de Janeiro: Record, 1990. p. 341.

45 Idem.

46 Idem.

${ }^{47}$ PITA, Sebastião da Rocha. Op. cit. p. 344-345.

${ }^{48}$ Ibidem. p.345-346.

${ }^{49}$ Treslado do requerimento que fez o Juiz do Povo e Mesteres sobre a moeda e prata feito aos 11 de fevereiro. In: Atas da Câmara 1684-1700. Op. cit. p. 202.

${ }^{50}$ Ibidem. p. 205.

${ }^{51}$ PITA, Sebastião da Rocha. Op. cit. p. 345-346.

${ }^{52}$ Idem.

${ }^{53}$ Carta de 27 de julho de 1680. In: Cartas do Senado 1673-1684. Op. cit. p. 83.

${ }^{54}$ Carta de lei de 8 março de 1694: Criação de Casa da Moeda na Bahia, levantamento do marco de ouro e prata. Disponível em http://iuslusitaniae.fcsh.unl.pt. Ius Lusitaniae: Fontes Históricas do Direito Português: Collecção Chronologica da Legislação Portugueza -1683-1700.

${ }^{55}$ Termo utilizado por Alfredo Bosi em Dialética da Colonização para se referir ao grupo que se desenvolveu junto com os engenhos de açúcar na primeira metade do século XVII e do qual Gregório de Matos era integrante. Conferir: BOSI, Alfredo. Dialética da colonização. $4^{\mathrm{a}}$ edição. SP: Companhia das Letras, 1992. p. 98.

\section{Referências bibliográficas:}

ALENCASTRO, Luis Felipe de. O trato dos viventes. Formação do Brasil no Atlântico sul. São Paulo: Companhia das Letras, 2000.

AZEVEDO, J. Lúcio de. Épocas de Portugal Económico: Esboços de História. 2a edição. Lisboa: Livraria Clássica Editora, 1947.

BLAKE, Augusto Victorino Alves Sacramento. Diccionario bibliographico brasileiro. Rio de Janeiro: Conselho Federal de Cultura, 1970. v. 7. Disponível em: <http://www.brasiliana.usp.br/handle/ 1918/00295770>. Acesso em: 15 nov. 2015.

BOSI, Alfredo. História concisa da literatura brasileira. São Paulo: Cultrix, 1970. Dialética da colonização. São Paulo: Companhia das Letras, 1992.

CANDIDO, Antonio. Literatura e sociedade. 8 ed. São Paulo: T. A. Queiroz, 2000. . Letras e ideias no Brasil colonial. In: HOLANDA, Sérgio Buarque de (dir.). História Geral da Civilização Brasileira. t. I, v. 2. $5^{\text {a }}$ ed. São Paulo: Difel, 1982. 
CARRARA, Angelo Alves. Receitas e despesas da Fazenda Real no Brasil: século XVII. Juiz de Fora: Editora UFJF, 2009.

COMPAGNON, Antoine. O demônio da teoria: literatura e senso comum. Tradução de Cleonice P. B. Mourão, Consuelo Fortes Santiago. Belo Horizonte: Ed. UFMG, 2003.

Documentos Históricos do Arquivo Municipal da Bahia. Atas da Câmara 1659-1669. $4^{\circ}$ volume. Salvador: Prefeitura do Município de Salvador, 1949.

Atas da Câmara 1684-1700. $6^{\circ}$ volume. Salvador: Prefeitura do Município de Salvador, Bahia, 1951.

. Cartas do Senado 1673-1684. $2^{\circ}$ Volume. Salvador: Prefeitura do Município de Salvador, Bahia, 1952.

- Cartas do Senado: 1684- 1692. $3^{\circ}$ Volume. Salvador: Prefeitura do Município de Salvador, Bahia, 1953.

FERLINI, Vera Lúcia A. Terra, trabalho e poder. São Paulo: Brasiliense; 1988.

GODINHO, Vitorino de Magalhaes. 1580 e a Restauração. IN: Ensaios. Lisboa: Sá da Costa, 1968.

HANSEN, João Adolfo. A sátira e o engenho: Gregório de Matos e a Bahia do século XVII. São Paulo: Companhia das Letras; Secretaria de Estado da Cultura, 1989.

HANSON, Carl. Economia e sociedade no Portugal barroco: 1668-1703. Lisboa: Dom Quixote, 1986.

HECKSCHER, Eli F. La epoca mercantilista: historia de la organización y las ideias econômicas desde el final de la Edad Media hasta la sociedad liberal. México: Fondo de Cultura Económica, 1983.

HUTTER, Lucy Maffei. Navegação nos séculos XVII e XVIII: rumo: Brasil. EdUSP, 2005.

MARCADÉ, Jacques. O quadro internacional e imperial. In: MAURO, In: SERRÃO, Joel; MARQUES, A. H. de Oliveira (direcção). Nova história da Expansão Portuguesa. Vol. VII. Lisboa: Estampa, 1991

MATOS, Gregório de. Crônica do viver baiano seiscentista. Organização de James Amado. Bahia: Janaína, 1990.

MAURO, Frédéric. Portugal, Brasil e o Atlântico. 1570 - 1670. Tradução Manuela Barreto. Editorial Estampa, 1988.

PERES, Fernando da Rocha. Gregório de Matos: o poeta devorador. Rio de Janeiro: Manati, 2004.

PITA, Sebastião da Rocha. História da América Portuguesa. Lisboa: Officina de Joseph Antonio da Sylva Impressor da Academia Real, 1730.

RABELO, Manuel Pereira. Vida e Morte do Doutor Gregorio de Mattos e Guerra, Escrita pelo Licenciado Manuel Pereyra Rabello. In: GUERRA, Gregorio de Matos e. Obras Sacras e Divinas. Tomo I, I e II parte. Cofre 50, Códice 56, Seção de manuscritos da Biblioteca Nacional do Rio de Janeiro.

SCHWARTZ, Stuart B. Segredos Internos: engenhos e escravos na sociedade colonial, 15501835. São Paulo: Companhia das Letras, 1995.

SPINA, Segismundo. A poesia de Gregório de Matos. São Paulo: USP, 1995. 